\title{
Permeability Estimation for Carbonate Reservoir (Case Study/ South Iraqi Field)
}

\author{
Samaher A. Lazim ${ }^{\text {a }}$, Sameera M. Hamd-Allah ${ }^{\mathrm{b}}$ and Ali Hussain Jawad \\ ${ }^{a}$ Petroleum Technology Department/ Uni. of Technology \\ ${ }^{b}$ Petroleum Eng. Dept./College of Eng./ Baghdad Uni. \\ ${ }^{c}$ Ministry of Oil/ Iraq
}

\begin{abstract}
The heterogeneity nature of carbonate reservoirs shows sever scattering of the data, therefore, one has to be cautious in using the permeability- porosity correlation for calculating permeability unless a good correlation coefficient is available. In addition, a permeability- porosity correlation technique is not enough by itself since simulation studies also require more accurate tools for reservoir description and diagnosis of flow and non-flow units.

Evaluation of reservoir characterization was conducted by this paper for Mishrif Formation in south Iraqi oil field (heterogeneous carbonate reservoir), namely the permeability-porosity correlation, the hydraulic units (HU's) and global hydraulic elements (GHE) methods depending on Reservoir Quality Index(RQI) concepts.
\end{abstract}

Keywords: Permeability, Carbonate reservoir,Mishrif Formation, GHE.

Received on 30/05/2013, Accepted on 22/05/2018, Published on 3010912018

https://www.doi.org/10.31699/IJCPE.2018.3.5

\section{1- Introduction}

Knowledge of permeability distribution is critical to effective reservoir description. Carbonate reservoirs consist of limestone and dolomite, they are generally less homogeneous than clastic reservoirs and have a wide range of grain size distributions. Typically carbonates have very low matrix permeability, as low as 0.1 to 1.0 md in some cases, but carbonates often have extensive natural fracture systems. Significant permeability is possible from secondary porosity associated with features such as vugs and oolites. Permeability and permeability distribution are usually determined from core data. However, most wells are often not cored, as a result, permeability is estimated in uncored sections/ wells from permeability versus porosity relationships that are often developed from statistically insignificant data sets.

\section{2- Discussion}

2.1. Relationship of Porosity to Permeability for core plugs data

The extreme petrophysical heterogeneity found in carbonate reservoirs is clearly demonstrated by the wide variability observed in porosity- permeability cross-plots of core analysis data. Permeability in particular, can vary by a factor of 10 or more at the small scale and is nearly randomly distributed.
Correlation between porosity and permeability for a particular rock type is a basic procedure applied in coredata interpretation. However, this correlation may not always be satisfactory because of pore heterogeneity and pore geometry. In general, the log of permeability is linear with porosity for a given rock type, however, the precise relationship is found only through direct measurements of representative rock samples. In uncored wells or zones, empirical permeability is estimated from log derived porosity using the following equation:

$\log k=a * \emptyset+b$

There is apparently no theoretical basis to support the traditional cross plot of the logarithmic of permeability versus porosity. Permeability is plotted as log function only because it appears to be log-normally distributed. On the classical plot, the relationship between permeability and porosity is not causal. Whereas porosity is generally dependent of grain size, permeability is strongly dependent on grain size, for example, in a reservoir, porosity and permeability may, in general, be directly proportional. However, in the same reservoir, there may be both high and low permeability zones.

The core plug porosity values for some drilling wells in the studied reservoir (Mishrif Fm.) are plotted against logarithm of air permeability, Fig. 1.

A linear regression was run between them and the resulting equation is: 
$K=14.663 * \varphi-2.0937$

The regression coefficient $\left(\mathrm{R}^{2}\right)$ was obtained as $(63.55$ $\%$ ) meaning that there exists an unreasonable relation between the parameters. An increase in porosity is followed by an increase in permeability, but for samples, the amount of increase in porosity is not directly proportional to permeability, due to of isolated pores that do not contribute to permeability.

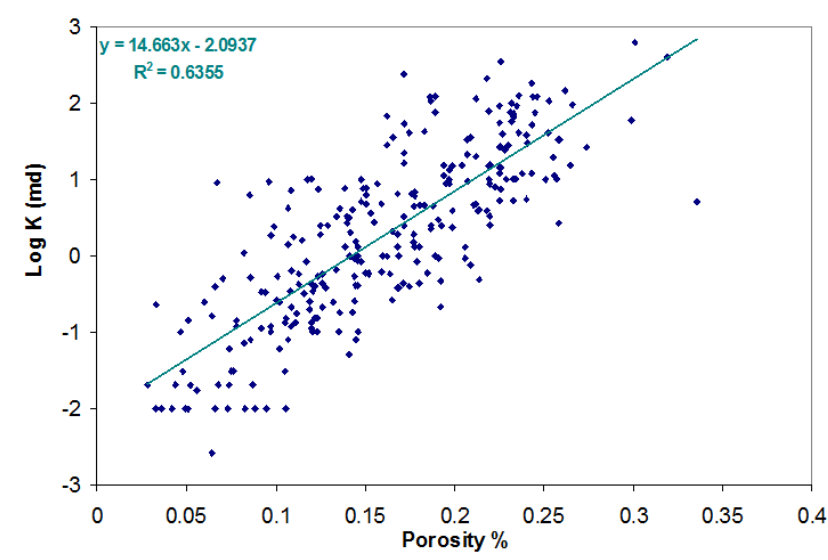

Fig. 1. Permeability- Porosity Relationship from Core Plugs/ Mishrif Formation

\subsection{Permeability Estimation by Using Global Hydraulic} Element (GHE) Method

\section{a. Hydraulic Unit (HU)Concept}

Characterization of carbonate reservoir into flow units is a practical way of reservoir zonation. The presence of distinct units with particular petrophysical characteristics such as porosity, permeability, water saturation, pore researches to establish strong reservoir characterization.

The earlier in the life of a reservoir the flow unit determination is done, the greater the understanding of the future reservoir performance. A quality and the future performance of a reservoir are controlled by hydrocarbon storage and flow capacity.
These help to define intervals of similar and predictable flow characteristics, which are the flow units.

The term flow unit has been used originally to describe the correlation units in reservoirs [4]. A flow unit (or hydraulic flow unit) is defined as the representative elementary volume of total reservoir rock within which geological and petrophysical properties that affect fluid flow are internally consistent and predictably different from properties of other rock volumes [1] \& [7], introduced the term "Flow Unit" to describe geological units within a stratigraphic framework that have petrophysical properties within certain ranges.

The HU's for a hydrocarbon reservoir can be determined from core analysis data (porosity \& permeability).

This technique has been introduced by [1] and involved calculating the Flow Zone Indicator (FZI) from the pore volume to solid volume ratio $\left(\varphi_{\mathrm{z}}\right)$ and Reservoir Quality Index (RQI) via equation (3):

$F Z I=\frac{R Q I}{\varphi_{Z}}=\frac{0.0314 \sqrt{\frac{k}{\varphi}}}{\left(\frac{\varphi}{1-\varphi}\right)}$

All available porosity and permeability data from core plugs analyses for six wells were used to develop a representative training data base for HU classification.

When plotting RQI versus $\varphi_{Z}$ on $\log$ - $\log$ scale, all core samples with similar FZI values will lie on a straight line with a unit slop [1]. Other core samples that have different FZI values lie on other parallel lines.

Unfortunately, this is not always the case, in fact[2]\& [6] showed that natural rock systems tend to show various slops rather than having a fixed slop as suggested by [1] and the K-C model, Fig. 2. From FZI values, samples can be classified into different HU's. samples with a similar FZI value belong to the same HU. [8] \& [9], Fig. 3 shows the HU approach which applied to Mishrif Formation in the studied field where three distinct HU's are evident with different number of HU and these were defined by different FZI relationships. Accordingly, the porosity- permeability relationships for different HU systems were estimated.

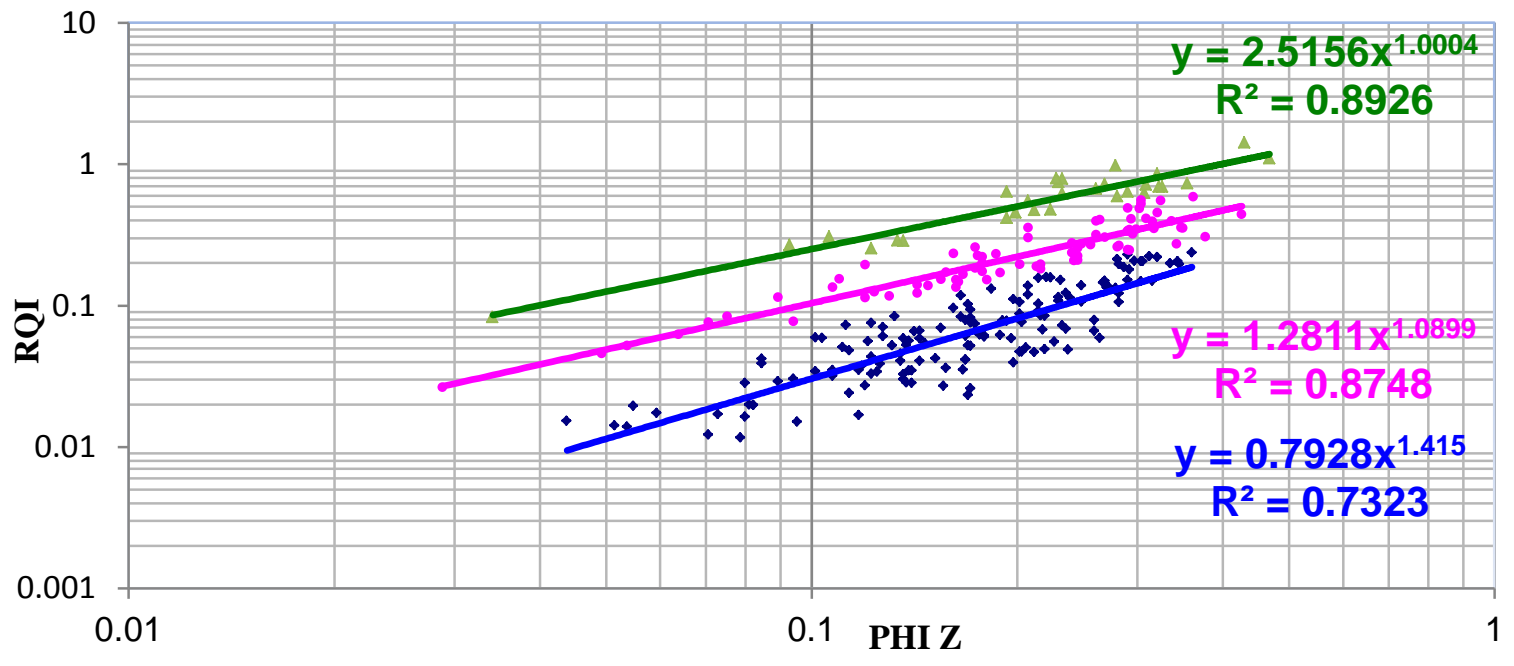

Fig. 2. RQI vs. $\Phi_{\mathrm{Z}}$ Relationships for Different HU Systems 


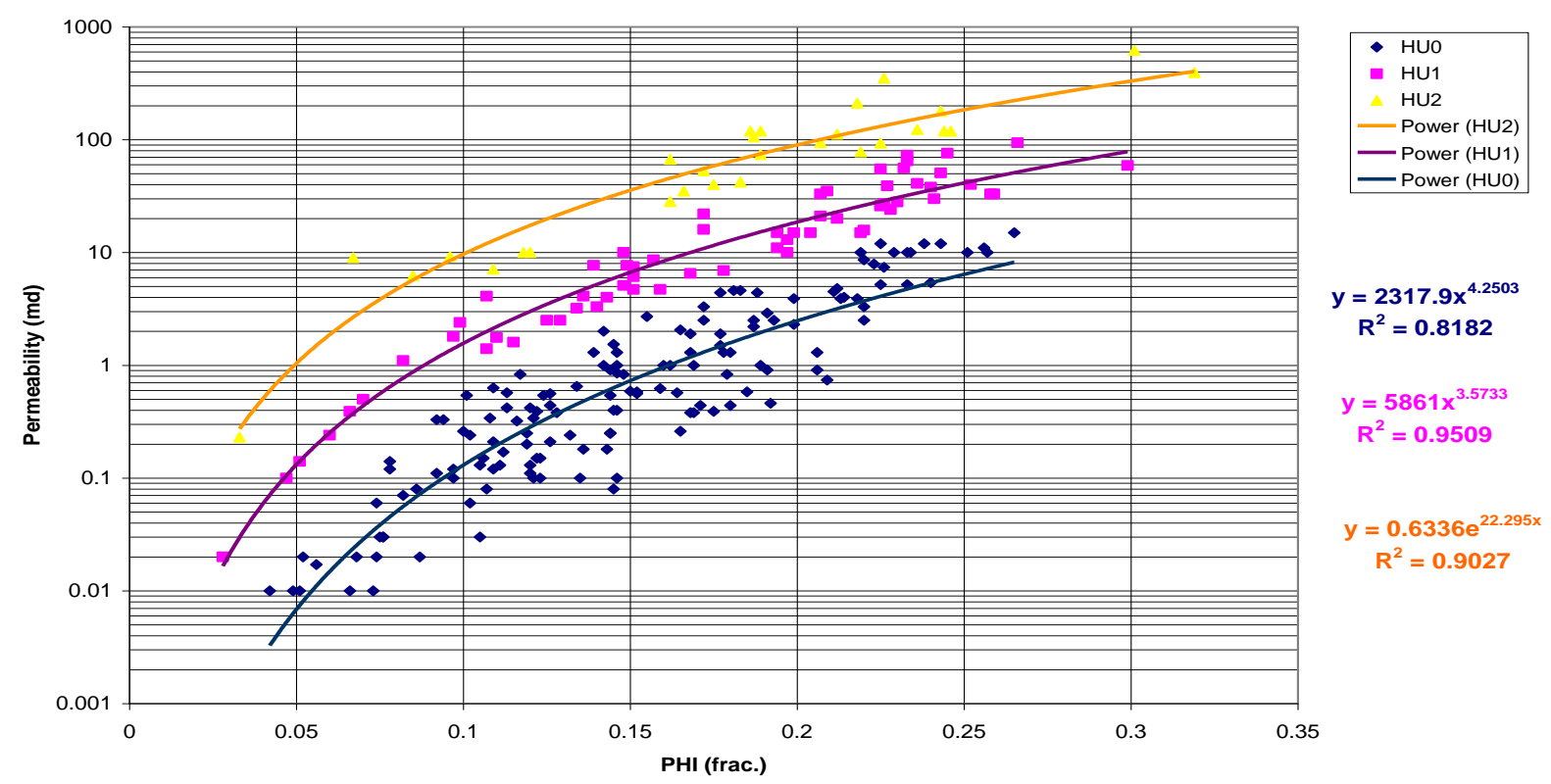

Fig. 3. Porosity- Permeability Relationships for Different HU Systems

\section{b. Global Hydraulic Element (GHE)}

Petrophysists have long tried to define a hydrocarbonbearing reservoir as a limited set of elements number with unique characteristic of each one. To address this issue, [1] introduced the first approach of the hydraulic flow units (HFU) concept. This concept was successful in determining different systems in a single data set, such as a cored well, but this method has one major limitation, that different HFU's were found in each well. This limitation is overcomed by the new concept of petrotyping using Global Hydraulic Elements (GHE) which was developed in a series of studies [3], [5] \& [10].

The GHE approach also based on Flow Zone Indicator (FZI) values from the same underlying theory as Hydraulic Units (HU). However, the selecting of a systematic series of FZI values allows determination of Hydraulic Unit (HU) boundaries to define ten Global Hydraulic Elements that can be applied to any reservoir formation.

The definition of these boundaries is arbitrary chosen in order to split a wide region of possible combinations of porosity and permeability into a manageable number of Global Hydraulic Elements, [4] \& [5].

Petrophysical rock typing is a necessity in carbonate reservoirs. Occasionally it will occure as a single GHE class (uni- petrotype) such as the case of chalk, which is a texturally controlled media with a very fine grain size, so simpler relationships may be observed, i.e. carbonate reservoirs can have simple (uni- petrotype, such as a chalk) to very complex (multi- petrotype) distributions of GHE's.

The GHE approach sets a framework for determining how many rock types are needed for reservoir description, and can be used for permeability prediction.
For a given porosity, the permeability can be calculated by a rearrangement of equation (3) as follows:

$\mathrm{k}=\varphi\left[F Z I\left(\frac{\varphi}{1-\varphi}\right) / 0.0314\right]^{2}$

And using this equation, lines for constant FZI can be determined.

The Global H ydraulic Element (GHE) approach has been applied for the studied area (Tuba Oil Field, Mishrif formation/ Basra) to improve the reservoir description and identify significant trends of Mishrif formation. Four Global Hydraulic Elements are identified for drilling wells in the studied reservoir.

The GHE template identifies three poro- perm clusters, Fig. 4, which can be modeled using a simple FZI value about which to distribute permeability for a given porosity, FZI of (0.28) for cluster (1), ( 0.75 ) for cluster ( 2 ), and (2.2) for cluster (3).

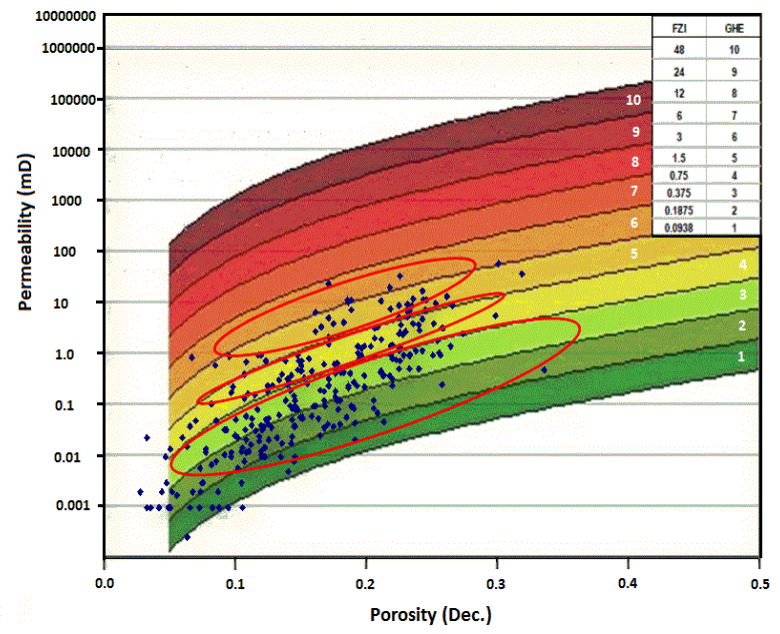

Fig. 4. Porosity- Permeability Data Drawn on Standard GHE Plot 


\section{3- Conclusions}

1- The routine and special core analysis (SCAL) data and core description data are taken as "ground truth" for petrophysical model calibration. Over (272) of core from (6) wells have been obtained, described, and analyzed.

2- Carbonate rock data show scattering and poor correlation on permeability vs. porosity plot, thus, it is better to use the three relationships among porosity and permeability to represent rock types for permeability calculation.

3- Three relationships of permeability- porosity for Mishrif Fm. which is carbonate reservoir in the studied field were estimated according to different HU'S systems and depending on Reservoir Quality Index (RQI) concepts.

4- Three poro- perm clusters for the reservoir under study could be found by the GHE template in which FZI values should be used to estimate permeability for a given porosity.

\section{Nomenclature}

FZI : Flow zone indicator, $\mu \mathrm{m}$

HU : Hydraulic flow unit

$\mathrm{K} \quad$ : Permeability, $\mathrm{mD}$

RQI : Reservoir Quality Index, $\mu \mathrm{m}$

\section{Greek Symbols}

$\varphi \quad$ : Porosity, fraction

$\varphi_{\mathrm{z}} \quad$ : Normalized porosity index, fraction

\section{References}

[1] Amaefule, J.O., et al.; 1993." Enhanced Reservoir Description: Using Core and Log Data to Identify Hydraulic (Flow) Units and Predict Permeability in Uncored Intervals/ Wells". SPE paper 26436, Annual Technical Conference and Exhibition, Houston, Texas.

[2] Civan, F.; 2002: "Fractal Formulation of the Porosity and Permeability Relationship Resulting in a PowerLaw Flow Units Equation- A Leaky- Tube Model." SPE 73785, SPE International Symposium and Exhibition on Formation Damage Control, Lafayette, Louisiana.

[3] Corbett, P. W. M., Ellabad, Y., Mohammed, K., \&Posysoev, A.; 2003."Global Hydraulic Elements: Elementary Petrophysics for Reduced Reservoir Modeling." European Association of Geoscientists and Engineers $65^{\text {th }}$ Conference (EAGE), Annual Technical Meeting.

[4] Corbett P.W.M. and Potter D.K.; 2004 "Petrotyping: A Basemap And Atlas For Navigating Through Permeability And Porosity Data For Reservoir Comparison And Permeability Prediction". Institute of Petroleum Engineering, Heriot-Watt University,
Edinburgh, EH14 4AS, UK This paper was prepared for presentation at the International Symposium of the Society of Core Analysts held in Abu Dhabi, UAE.

[5] Ebanks, W. J., Jr. Scheihing, M. H., \& Atkinson, C.D.; 1992: "Flow Unit for Reservoir Characterization in Development Geology Reference Manual." Morton-Thompson and Woods (Eds.) AAPG Methods in Exploration 10, p. 282-285.

[6] Haro, C.F.; 2004: "The Perfect Permeability Transform Using Logs and Cores." SPE 89516, Annual Technical Conference and Exhibition, Houston, Texas.

[7] Hearn, C.L. Ebanks, W.J. Tye. R.S.\&Ranganathan. V.; 1984: "Geological Factors Influencing Reservoir Performance of Hartzog Draw FieldWyoming." JPT V. 36, No. 9, p. 1335-1344.

[8] Mohammed, K.; 2002: "Petro physical Characterization of Solution Seams and Optimization of Hydraulic Units in a clastic Reservoir." Ph.D. Thesis, Heriot Watt University, 300p.

[9] Mohammed, K.\& Corbett, P.W.M.; 2002: “ How Many Relative Permeability Measurements Do you Need? A Case study from a North African Reservoir" Proceedings of the 2002 International Symposium of the Society of Core Analysts, Paper SCA 2002-03.

[10] Svrisky, D., Ryazanov, A., Pankov, M., Corbett, P.W.M., \&Posysoev, A.; 2004: "Hydraulic Flow Units Resolve Reservoir Description Challenges in a Siberian Oil Field." SPE 87056, SPE Asia Pacific Conference on Integrated Modelling for Asset Management, Kuala Lumpur, Malaysia. 


\section{تقييم النفاذية للمكمن الكربوني (دراسة حالة/حقل جنوب العراق)}

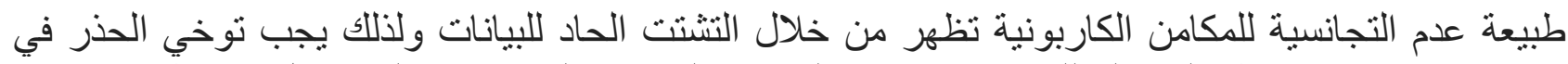

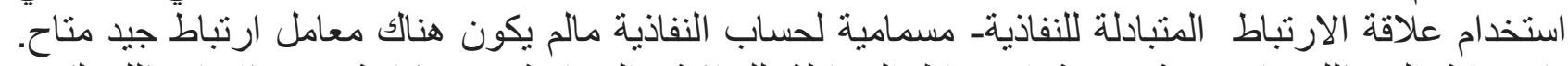

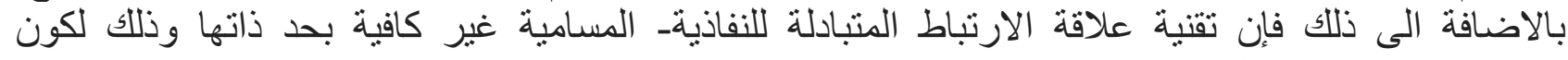

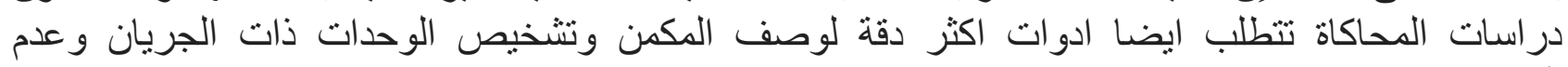
الجريان.

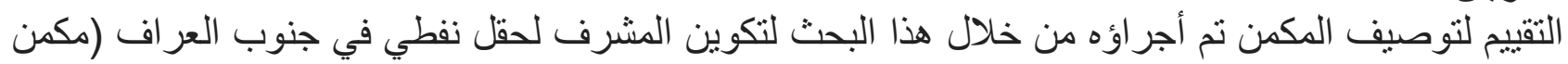

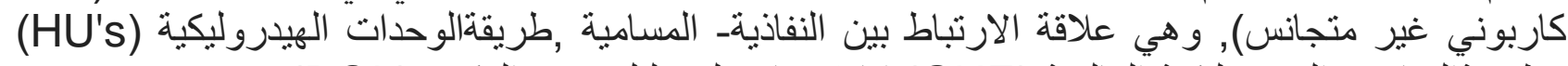

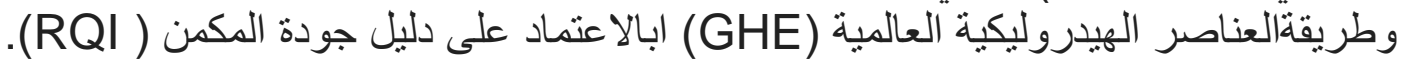

